\title{
Immuno-oncology: a narrative review of gastrointestinal and hepatic toxicities
}

\author{
Stergios Boussios ${ }^{1,2,3}$, Matin Sheriff ${ }^{4}$, Elie Rassy ${ }^{5,6}$, Michele Moschetta ${ }^{7}$, Eleftherios P. Samartzis ${ }^{8}$, \\ Rachel Hallit ${ }^{9}$, Agne Sadauskaite ${ }^{10}$, Konstantinos H. Katsanos ${ }^{11}$, Dimitrios K. Christodoulou ${ }^{11}$, \\ Nicholas Pavlidis ${ }^{12}$
}

${ }^{1}$ King's College London, Faculty of Life Sciences \& Medicine, School of Cancer \& Pharmaceutical Sciences, SE1 9RT, London, UK; ${ }^{2}$ Department of Medical Oncology, Medway NHS Foundation Trust, Windmill Road, ME7 5NY, Gillingham, Kent, UK; ${ }^{3}$ AELIA Organization, 9 th Km Thessaloniki - Thermi, Thessaloniki, Greece; ${ }^{4}$ Department of Urology, Medway NHS Foundation Trust, Windmill Road, Gillingham, Kent, ME7 5NY, UK; ${ }^{5}$ Department of Cancer Medicine, Gustave Roussy Institut, Villejuif, France; ${ }^{6}$ Department of Hematology-Oncology, Hotel Dieu de France University Hospital, Faculty of Medicine, Saint Joseph University, Beirut, Lebanon; ${ }^{7} \mathrm{CHUV}$, Lausanne University Hospital, Rue du Bugnon 21 CH-1011, Lausanne, Switzerland; ${ }^{8}$ Department of Gynecology, University Hospital Zurich, Frauenklinikstrasse 10, CH-8091 Zurich, Switzerland; ${ }^{9}$ Gastroenterology Department, Cochin University Hospital, Assistance Publique-Hôpitaux de Paris and University of Paris, Paris, France; ${ }^{10}$ Department of Pharmacy, Medway NHS Foundation Trust, Gillingham, Kent, UK; ${ }^{11}$ Department of Gastroenterology, University Hospital of Ioannina, Faculty of Medicine, School of Health Sciences, University of Ioannina, Ioannina, Greece; ${ }^{12}$ Medical School, University of Ioannina, Ioannina, Greece

Contributions: (I) Conception and design: S Boussios, KH Katsanos, DK Christodoulou, N Pavlidis; (II) Administrative support: All authors; (III) Provision of study materials or patients: All authors; (IV) Collection and assembly of data: All authors; (V) Data analysis and interpretation: All authors; (VI) Manuscript writing: All authors; (VII) Final approval of manuscript: All authors.

Correspondence to: Dr. Stergios Boussios, MD, PhD, MRCP. Honorary Senior Lecturer, King's College London, Faculty of Life Sciences \& Medicine, School of Cancer \& Pharmaceutical Sciences, London, UK; Consultant Medical Oncologist, Medway NHS Foundation Trust, Kent, UK. Email: stergiosboussios@gmail.com, stergios.boussios@nhs.net and stergios.boussios@kcl.ac.uk.

\begin{abstract}
Vaccines, cytokines, and adoptive cellular therapies (ACT) represent immuno-therapeutic modalities with great development potential, and they are currently approved for the treatment of a limited number of advanced malignancies. The most up-to-date knowledge on the regulation of the anti-cancer immune response has recently led to the development and approval of inhibitors of immune checkpoints, which have produced unprecedented clinical activity in several hard to treat solid malignancies. However, severe adverse events (AEs) represent a limitation to the use of these drugs. Currently approved checkpoint inhibitors block cytotoxic T-lymphocyte-associated antigen 4 (CTLA-4), programmed cell death protein (PD-1) and its ligand (PD-L1), resulted in increased survival of patients with several solid and hematologic malignancies. The most common treatment AEs associated with these drugs are fatigue, rash, and autoimmune/inflammatory reactions. Many of the immune-related AEs are reversible and the strategies for their management include supportive care either with or without treatment withdrawal; nevertheless, in severe cases, hospitalization and treatment with immune suppressants, and/or immunomodulators may be required. Steroid therapy is a critical component of the treatment algorithm; nevertheless, the associated immunosuppression may compromise the antitumor response. This article provides a comprehensive and narrative review of luminal gastrointestinal and hepatic complications, including recommendations for their investigation and management.
\end{abstract}

Keywords: Vaccines; cytokines; cellular therapy; checkpoint inhibitors; toxicity

Submitted Nov 09, 2020. Accepted for publication Jan 17, 2021.

doi: 10.21037/atm-20-7361

View this article at: http://dx.doi.org/10.21037/atm-20-7361

^ ORCID: 0000-0002-2512-6131. 


\section{Introduction}

Cancer immunotherapy was originally initiated 100 years ago, through intratumoral injections of Streptococcus or Serratia marcescens (1). In the last twenty years, a number of ligand-targeting drugs have been incorporated in clinical practice, improving the prognosis of several malignancies. This oncological breakthrough presents new challenges in recognizing and managing treatment-mediated adverse events (AEs).

In the tumor microenvironment, immunosuppressive molecules such as cytotoxic T-lymphocyte-associated antigen 4 (CTLA-4), programmed cell death protein (PD-1) and its ligand (PD-L1) are overexpressed (1). CTLA-4 is an inhibitory co-receptor, expressed on the surface of activated T CD4+ and CD8+ lymphocytes that shares significant homology with CD28. Furthermore, it binds the same B7.1 and B7.2 ligands, which are costimulatory molecules on the antigen-presenting cell surface. Importantly, CTLA4 has a 100-fold higher affinity with the B7 complex than CD28, and this interaction counteracts CD28-mediated costimulatory signals, compromising the activation of $\mathrm{T}$ cells. PD-1 is expressed more broadly than CTLA-4 and can be detected on activated $\mathrm{B}$ cells, monocytes, and natural killer T cells (2). PD-L1, a ligand that PD-1 interacts with, is upregulated in solid tumors. Signaling through this pathway results in the inhibition of cytokine production and apoptosis of PD-1 expressed, tumor-infiltrating T cells (3). PD-L1 is expressed on leukocytes, nonhematopoietic cells, and some nonlymphoid tissues (4).

Generally, it seems that cytokines such as interleukin-2 and interferon- $\alpha$, induce a more diffuse non-specific $\mathrm{T}$ cell response, whilst checkpoint protein inhibitors, vaccines, and adoptive cellular therapies (ACT) are correlated with a more specific $\mathrm{T}$ cell activation, resulting in damage to specific organs. Furthermore, CTLA-4 inhibitors mediated toxicities are usually more severe than those related to PD-1 and PDL1 inhibitors. This is probably associated with the observation that PD-1 signaling acts more peripherally than CTLA-4 (5). AEs are mostly managed by counteracting lymphocyte activation with steroids; nevertheless, the associated immunosuppression may compromise the antitumor response (6). The successful and safe implementation of novel immunotherapies in daily oncological practice requires clinicians to be aware of their mechanisms of action and the associated AEs. This narrative review aims to summarize the gastrointestinal and hepatic AEs of the novel immunotherapy agents, along with the recommended management, mainly focusing on immune checkpoint CTLA-4 and PD-1/PDL1 inhibitors. We present the following article in accordance with the Narrative Review reporting checklist (available at http://dx.doi.org/10.21037/atm-20-7361).

\section{Methods}

Medline/PubMed and Google Scholar was searched until October 2020 for publications in the English language reporting on gastrointestinal and hepatic AEs of the novel immunotherapy agents. The search was carried out using mainly ("Immunotherapy"[Mesh]) AND "Gastrointestinal, Hepatic AEs"[Mesh]) in Medline or the following keywords such as "vaccines", "cytokines", "cellular therapy", "checkpoint inhibitors", "toxicity", "colitis", "hepatitis" in Google Scholar. The screening of the articles was performed manually, based on the publication titles and abstracts. Of the articles retrieved, the reference lists of the relevant papers were checked to detect other articles that may be of interest to our narrative review.

\section{Toxicities of cancer vaccines}

Sipuleucel-T was the first cancer vaccine approved in April 2010 by the United States Food and Drug Administration (FDA) for the treatment of castration-resistant prostate cancer. This is an autologous vaccine, prepared by a $250-\mathrm{mL}$ suspension containing a minimum of 50 million autologous CD54+ cells, activated with prostate acid phosphatase-granulocyte-macrophage colony-stimulating factor (7). When sipuleucel-T is infused into the patient, the activated antigen-presenting cells displaying the fusion protein induce anti-tumor immunity.

The efficacy of sipuleucel-T was investigated in the phase III IMPACT trial that enrolled asymptomatic or minimally symptomatic patients with metastatic castrationresistant prostate cancer, no visceral metastases, and serum prostate-specific antigen (PSA) levels of $\geq 5.0 \mathrm{ng} / \mathrm{mL}$ (7). Median overall survival (OS) in the experimental group was extended by 4.1 months compared to the placebo group (25.8 compared to 21.7 months), which was statistically significant [hazard ratio (HR) 0.775 ; 95\% CI (confidence interval): 0.614-0.979; $\mathrm{P}=0.032$ ].

Sipuleucel-T has mild toxicity and common AEs at a rate $\geq 15 \%$ include chills, fatigue, fever, back pain, joint ache, headache, nausea, and anemia. These toxicities occurred within the first few days of treatment and dissipated within one or two days (7). Among 601 patients randomly assigned 
to sipuleucel-T and placebo, who underwent leukapheresis at least once, $95.1 \%$ reporting acute infusion reactions (8). However, severe or life-threatening AEs were equal between the experimental and placebo arm $(27.6 \%$ and $28.4 \%$, respectively).

The disease-specific prophylactic and therapeutic vaccines also include peptide-based counterparts. Epitope specificity for $\mathrm{T}$-cells is mediated by the $\mathrm{T}$-cell receptor (TCR), which binds peptides presented in the peptidebinding groove of major histocompatibility complexes class I and class II on antigen-presenting cells (APCs). As such, there is a lower risk of causing pathogenic or offtarget responses as compared to conventional vaccines. However, there are some concerns related to peptide vaccine treatment. Firstly, as they are human leukocyte antigen (HLA) restricted, it should be known patients' HLA type. Furthermore, they have a weaker overall immune response, in comparison to vaccines that contain inactivated or attenuated pathogens. Regardless of these limitations, peptide vaccines represent an interesting treatment strategy, based on their ability to stimulate antigen-specific immune responses, along with the favorable toxicity profile.

Beyond peptide-based, there have also been investigated tumor vaccines, based on the use of whole cells from the tumor as the source of immunogenic material. In most models of this type of vaccination, there is a requirement for T-cell activation; nevertheless, cells of the innate immune system, including natural killer cells, macrophages, and eosinophils have also been implicated. These vaccines can be either autologous or allogeneic (9). In contrast to peptide-based vaccines, target antigens are not required to be prospectively identified in this vaccine treatment. Regardless of immune responses and tumor regression in murine tumor models (10-13), reports from several clinical trials in melanoma, prostate, pancreatic, and lung cancer were suggestive of limited efficacy despite immune responses (14-17). M-Vax represents an autologous tumor-cell vaccine and treated patients with tumor regression, achieved statistically significant longer median OS, as compared to those without tumor regression (21.4 vs. 8.7 months; $\mathrm{P}=0.01$ ) (18). Treatment-induced toxicities consisted of pustules or papules with small ulcerations at the injection site, whereas less than $5 \%$ of patients experienced fever or malaise within 24 hours following vaccine treatment (18).

\section{Toxicities of cytokines}

Cytokines are naturally produced by numerous cell types and serve as mediators of cellular differentiation, inflammation, immune pathology, and regulation of immune response. A balance between pro-inflammatory and anti-inflammatory cytokines is essential component of host immunity against microbes as well as malignant cells (19). Cytokines can be divided into several subcategories, including among others the interferons, and interleukins (20).

Type I IFN family consists of IFN- $\alpha$, IFN- $\beta$, IFNA- $\varepsilon$, IFN- $\kappa$ and IFN- $\omega$ cytokines. Among numerous IFN-a subtypes, IFN-a2b is the most widely used in cancer immunotherapy (21). FDA approved recombinant human IFN-a2 for treatment of hairy cell leukemia, and advanced melanoma in 1986 and 1996, respectively $(22,23)$. The objective response rates (ORR) of IFN- $\alpha 2 \mathrm{~b}$ in patients with advanced melanoma is $22 \%$ (24); nevertheless, the OS has been improved only by approximately 4 months (25). In the era of molecularly targeted therapies and checkpoint inhibitors, IFN- $\alpha$ is occasionally but not routinely used in clinical practice (26).

The most common AEs of IFN-a are the flulike symptoms, which may be severe, but equally are rapidly reversible, when treatment is withheld (27). Moreover, IFN-a treatment may also cause thyroid derangement, neuropsychiatric symptoms, anorexia, and hepatic dysfunction $(28,29)$. Mild elevations in liver aminotransferases without clinical symptoms are common. IFN-a should be suspended in patients with grade 3 hepatotoxicity, until a decrease of the aminotransferases concentration reach 1.5 times of normal level, when deemed safe to restart treatment a $30 \%$ dose reduction is recommended. In the Eastern Cooperative Oncology Group (ECOG) Trial E1684, 46\% of enrolled patients receiving IFN-a experienced nausea and vomiting, whereas $2 / 3$ had early satiety, anorexia, and weight loss (30). Symptoms' control required non-steroidal anti-inflammatory agents and IFN-a dose modifications.

Interleukin-2 (IL-2) was initially characterized in the 1970s as a T-cell growth factor. High-dose cytokine of IL-2 was approved by the FDA for the treatment of metastatic renal cell carcinoma or melanoma in 1992 and 1998, respectively. The mechanism of the severe toxicities of IL-2 is related to the stimulation of proinflammatory cytokines, leading to vasopermeability, vascular leak, and a sepsislike syndrome. Capillary leak syndrome may clinically cause hypotension, cardiac arrhythmias, angina, myocardial infarction, and pleural effusion (31). Additional AEs include gastrointestinal bleeding, diarrhea, nausea, and liver failure with hypertransaminasemia and hyperbilirubinemia (32). 
Despite the fact that the AEs of high-dose IL-2 treatment may be severe, they equally are rapidly reversible. Treatment cessation temporarily in view of patient recovery is recommended. Early administration of dopamine may maintain organ perfusion and preserve urine output. Glucocorticoids are considered for the management of IL2-induced AEs, including hyperbilirubinemia.

\section{Toxicities of adoptive cell therapy}

ACT is the transfer of patient-derived naturally occurring or genetically modified $\mathrm{T}$ cells that have been expanded and manipulated ex vivo back into patients to treat metastatic cancers or advance/refractory hematological malignancies. Based on the mechanism of action, it is classified into ACT with tumor-infiltrating lymphocytes (TILs), ACT with chimeric antigen receptor (CAR) modified $\mathrm{T}$ cells, and ACT using TCR gene therapy (33).

Adoptive cell therapy of TILs has been widely investigated. In TILs-based protocols, patients were treated with non-myeloablative lymphodepleting chemotherapy (cyclophosphamide and fludarabine), prior to infusion of TILs $\left(10^{10}-10^{11}\right.$ cells) followed by high-dose IL-2 therapy after TIL infusion $(34,35)$. In a study that investigated two different lymphodepleting approaches, enrolled patients with metastatic melanoma were treated with chemotherapy and total body irradiation in combination with IL-2 therapy (randomized to 2 and 12 Gy) (35). The achieved ORR for chemotherapy only arm, +2 and +12 Gy total body irradiation arms were $49 \%, 52 \%$, and $72 \%$, respectively. Treatment-induced toxicities were generally related to IL-2 administration or the preparatory lymphodepleting regimen. The latter is recommended to highly selected patients with reasonable performance status and high chances of successful TIL harvest.

Autologous T cells can be engineered to express CAR, composed of antigen-specific, antibody-binding domains connected to T-cell-activating domains. The first generation of CAR T cells was developed in 1993 (36), whilst in 1998 was introduced the co-stimulatory domain (37). In 2003, second-generation CAR was developed to target CD19, which opened the way to the first successful treatment of a patient with ALL in 2011. The toxicity profile includes on-target toxicity as B-cell aplasia, hypogammaglobulinemia, and plasma cell reduction $(38,39)$. Peak serum cytokine levels were temporally associated with the peak concentration of CAR-expressing $\mathrm{T}$ cells that target CD19 and require initiation of tocilizumab (anti-IL6R
$\mathrm{Ab}$ ) and/or corticosteroids and close monitoring.

\section{Toxicities of checkpoint protein inhibitors}

Immune checkpoint inhibitors have been designed to directly target CTLA-4 and PD-1 immune checkpoints. There are two main policies related to the improvement of the response rate to immune checkpoint inhibitors. The first is based on the selection of patients within the context of specific predictive factors, such as PD-L1 expression, tumor mutational burden, and clinical features. The other highlights the enhancement of the efficacy of immune checkpoint inhibitors through the abscopal effect imediated by radiotherapy. More recently, several studies demonstrated the potential role of specific molecules in the modification of the immune microenvironment of the tumor and consequently the improvement of the response rate to immune checkpoint inhibitors. In this category of agents are included microbiota modifiers, drugs targeting co-inhibitory receptors, anti-angiogenic agents, small molecules, and oncolytic viruses. The incidence of most immune checkpoint inhibitors-mediated AEs appears to be broadly similar across tumor types (40).

\section{CTLA-4}

CTLA-4 is an inhibitory molecule that attenuates the activation of the $T$ cells by delivering inhibitory signals and competing with the molecule CD28 for binding to CD80 (B7.1) and CD86 (B7.2) (41). As CTLA-4 has higher affinity for these ligands, the co-stimulatory signal is eliminated and the lymphocytes are arrested in G1 of the cell cycle. Ipilimumab and tremelimumab are antiCTLA-4 blocking antibodies with demonstrated antitumor activity in patients with melanoma. Some studies support that ipilimumab-induced AEs predict antitumor efficacy in certain patients (42).

In a three-arms phase III trial, ipilimumab, with or without a glycoprotein 100 (gp100) peptide vaccine, was compared with gp100 alone in previously treated patients with metastatic melanoma (43). The median OS was 10.0 in the combination treatment arm, as compared with 6.4 months in those treated with gp100 alone (HR for death, $0.68 ; \mathrm{P}<0.001$ ), and 10.1 months in the ipilimumab cohort (HR for death in the comparison with gp100 alone, 0.66; $\mathrm{P}=0.003)$. The major immune-related AEs occurred in $60 \%$ of patients in the ipilimumab arm, versus $32 \%$ in those treated with the gp100 vaccine. Grade 3/4 immune- 
related AEs were detected in 10-15\% of ipilimumab-treated patients versus $3 \%$ in the gp100 cohort. The most frequent ipilimumab-induced $\mathrm{AE}$ was diarrhea, which was seen in $27-31 \%$ of patients. Furthermore, patients experienced injection-site reactions, vitiligo, endocrine-related AEs, and colitis. Ipilimumab may be suspended but patients should be followed-up for several months, as both responses and toxicities can be delayed. However, there is a lack of biomarkers that may predict either the efficacy or the risk of severe immune-mediated AEs of ipilimumab (44).

A randomized phase III study comparing treatment with tremelimumab (15 mg/kg once every 90 days) versus chemotherapy in treatment naïve patients with unresectable or metastatic melanoma, did not demonstrate survival benefit with tremelimumab (45). The estimated OS was 12.6 months (95\% CI: $10.8-14.3)$ for tremelimumab and 10.7 months (95\% CI: 9.36-11.96) for chemotherapy (HR, $0.88 ; \mathrm{P}=0.127)$. Tremelimumab-induced diarrhea or colitis was reported in $51 \%$ of patients, whilst $18 \%$ developed $\geq$ grade 3 diarrhea.

\section{Anti-PD-1}

PD-1 is a second immune checkpoint receptor, homologous to the CD28 family of protein receptors that is composed of an immunoglobulin V-like extracellular domain, a transmembrane domain, and an intracellular cytoplasmic domain $(46,47)$. PD-1 is expressed by $\mathrm{T}$ lymphocytes and upon interaction with PD-L1 or PD-L2 ligands, it functions as a co-inhibitory receptor that decreases $\mathrm{T}$ cell proliferation, apoptosis, and cytokine production. Additionally, PD-L1 contributes to the conversion of naive $\mathrm{CD}^{+} \mathrm{T}$ cells to regulatory $\mathrm{T}$ (Treg) cells and inhibits $\mathrm{T}$-cell responses by promoting the induction and maintenance of Tregs $(48,49)$. Nivolumab and pembrolizumab are monoclonal antibodies against the $\mathrm{PD}-1$ receptor.

The efficacy and tolerance of nivolumab have been evaluated in non-small cell lung cancer (NSCLC) patients in the second-line setting, following platinum-based doublet chemotherapy. In this setting, two phase III trials demonstrated improved OS and safer toxicity profile with the nivolumab ( $3 \mathrm{mg} / \mathrm{kg}$ every 2 weeks) versus docetaxel $\left(75 \mathrm{mg} / \mathrm{m}^{2}\right.$ every 3 weeks) in patients with advanced nonsquamous (CheckMate 057) and squamous (CheckMate 017) NSCLC. In the CheckMate 057, the OS was estimated 12.2 versus 9.4 months in favor of nivolumab (HR for death, 0.73; 96\% CI: 0.59 to $0.89 ; \mathrm{P}=0.002$ ) (50). The median OS in CheckMate 017 was 9.2 months in the experimental versus 6.0 months in the control arm, whilst the median progression-free survival (PFS) was 3.5 versus 2.8 months, respectively (HR for death or disease progression, 0.62 ; 95\% CI: $0.47-0.81 ; \mathrm{P}<0.001)$ (51). After 40.3 months' minimum follow-up in CheckMate 057 and 017, nivolumab maintained an OS benefit versus docetaxel. The estimated 3 -year OS rates were $17 \%$ (95\% CI: $14-21 \%$ ) versus $8 \%$ (95\% CI: 6-11\%) in the pooled population of both squamous and non-squamous NSCLC. As no patient remained on docetaxel treatment for more than 2 years, updated safety data are presented in nivolumab-treated patients only. The majority of treatment-induced select AEs occurred within the initial 3 months of nivolumab treatment (52). Moreover, in advanced renal cell carcinoma, the CheckMate 025 phase III trial reported a $27 \%$ risk reduction of death in the nivolumab arm, as compared to everolimus (53). Grade 3/4 treatment-related AEs occurred in $19 \%$ of the patients receiving nivolumab and in $37 \%$ of those treated with everolimus; the most common $\mathrm{AE}$ with nivolumab was fatigue ( $2 \%$ of the patients), whilst with everolimus the anemia ( $8 \%)$.

As far as pembrolizumab is concerned, a small phase I trial demonstrated early evidence of good clinical efficacy and favorable toxicity profile. In this trial with a classic $3+3$ escalation design, pembrolizumab was assessed at 1,3 , and $10 \mathrm{mg} / \mathrm{kg}$ in patients with advanced solid tumors, refractory to standard treatment (54). The maximum tolerated dose (MTD) was not reached, and then, an expansion cohort enrolled only those diagnosed with metastatic melanoma, treated with pembrolizumab at $10 \mathrm{mg} / \mathrm{kg}$ every 2 or 3 weeks or at $2 \mathrm{mg} / \mathrm{kg}$ every 3 weeks (55). All-grade drugrelated AEs were reported in $79 \%$ of participants, whereas only $13 \%$ experienced grade $3 / 4$ AEs, including rush and pruritus, hepatic and renal failure, fatigue and anorexia, diarrhea, abdominal pain, and hypothyroidism. Grade 1/2 gastrointestinal AEs such as diarrhea, nausea, and anorexia were reported in $30 \%$ of cases. Overall, AEs were more common with the higher-dose regimen.

In 2015 were published the results of the KEYNOTE-002 trial, which investigated pembrolizumab at 2 and $10 \mathrm{mg} / \mathrm{kg}$ every 3 weeks versus chemotherapy in immune checkpoint inhibitors refractory melanoma population. The grade 3/4 treatment-related AEs were 11 and $14 \%$, respectively (56). Specifically in the subgroup of pembrolizumab $10 \mathrm{mg} / \mathrm{kg}$, grade $3 / 4$ treatment-related AEs, included hypopituitarism, colitis, anorexia, and hyponatremia, along with diarrhea and pneumonitis, each of $1 \%$. More recently, KEYNOTE-006, a multicenter phase 
III study compared pembrolizumab with ipilimumab in ipilimumab-naive patients with stage III/IV melanoma (57). Median OS was 32.7 months in the combined pembrolizumab groups, compared to 15.9 months in the ipilimumab group (HR 0.73; 95\% CI: 0.61-0.88; $\mathrm{P}=0.00049)$. Median PFS was estimated 8.4 versus 3.4 months, respectively (HR 0.57 ; $95 \%$ CI: $0.48-0.67$; $\mathrm{P}<0.0001)$. The most common grade $3 / 4$ treatment-related AEs were colitis ( $2 \%$ in the combined pembrolizumab groups $v s .6 \%$ in the ipilimumab group), diarrhea ( $2 \% v s$. $3 \%$, respectively), and fatigue ( $<1 \% v s .1 \%$, respectively). Any-grade serious treatment-related AEs occurred in 14\% of patients in the combined pembrolizumab groups and $18 \%$ of those in the ipilimumab group. Among them, the most common were colitis ( $2 \%$ vs. $6 \%)$, diarrhea ( $1 \% v s$. $4 \%$ ), autoimmune hepatitis ( $1 \% v s .<1 \%)$, and pneumonitis $(1 \%$ vs. $<1 \%)$.

The anti-tumor activity of pembrolizumab has also been investigated in NSCLC, initially in the second- or even third-line setting. Based on the outcomes of KEYNOTE group of studies, it has been approved in the first-line treatment of unresectable advanced NSCLC. Indeed, KEYNOTE-189 established the antitumor activity and safety of pembrolizumab combined with chemotherapy for first-line treatment of metastatic NSCLC (58). The median OS in the intention to treat (ITT) population was 22 months in the pembrolizumab combination group, compared to 10.6 months in the placebo combination group, which led to the FDA approval in the first-line setting. A meta-analysis concluded that rates of immuneinduced AEs were increased with pembrolizumab combined approach, compared with standard treatment (59). Gastrointestinal manifestations occurred usually 5 to 10 weeks after treatment onset, and typically included diarrhea and colitis (60). The incidence of diarrhea is $5-10 \%$, usually mild or moderate (61), whereas the rate of colitis is $1.3 \%$, which increase to $11.8 \%$ in those treated with the combination (62). The most often liver toxicity is hepatitis with an incidence of less than $5 \%$, which most often occurs after 8 to 13 weeks of treatment introduction (63). It is reported that liver damage can be delayed until several years, following initiation of the treatment (64).

\section{Anti-PD-L1}

PD-L1 and PD-L2 are the two ligands for PD-1, and represent members of the $\mathrm{B} 7$ family of type I transmembrane protein receptors (46). The intracellular domain of PD-L1 is comprised of 30 amino acids. The protein is expressed on many cell types, including APCs, T cells, B cells, monocytes, and epithelial cells, and it is upregulated, following the response to proinflammatory cytokines, such as IFN- $\gamma$ and IL-4 (46,65). The approved by the FDA PD-L1 inhibitors are atezolizumab, durvalumab, and avelumab.

In vitro data suggest that atezolizumab, through the inhibition of PD-L1, may weaken immunosuppressive signals within the tumor microenvironment, enhancing $\mathrm{T}$ cell-induced immunity against tumors (66). From the clinical perspective, there is evidence supporting that it is efficacious and well-tolerated in several malignancies. In a phase I study, three dosing regimens for atezolizumab every 3 weeks were assessed in patients with recurrent NSCLC, melanoma, renal cell, colorectal, gastric, and head and neck squamous cell carcinoma (67). The reported MTD was $20 \mathrm{mg} / \mathrm{kg}$, whereas the achieved ORR was $21 \%$ across all histological types. Among AEs, the most frequently observed were fatigue, anorexia, nausea, pyrexia, diarrhea, rash, pruritus, arthralgia, and headache.

Likewise, a phase I escalation and expansion study evaluated the safety and efficacy of atezolizumab at a dose of $15 \mathrm{mg} / \mathrm{kg}$ every 3 weeks in heavily pre-treated patients with urothelial carcinoma, stratified by the PD-L1 expression (68). No dose-limiting toxicities were detected, following a median treatment duration of 65 days. The patients mostly experienced grade $1 / 2$ fatigue, nausea, anorexia, and pyrexia, many of which were transient. The reported ORR was $43 \%$ for the subset of $\mathrm{PD}-\mathrm{L} 1 \geq 5 \%$, versus $11 \%$ for $\mathrm{PD}-\mathrm{L} 1<5 \%$ (68). This was followed by a phase II trial of atezolizumab at a fixed dose of $1,200 \mathrm{mg}$ every 3 weeks, which demonstrated an ORR of $10 \%$ with prognostic association of PD-L1 expression (69). In May 2016, FDA granted accelerated approval to atezolizumab for locally advanced or metastatic urothelial carcinoma, in the subset of pre-treated with platinum-based chemotherapy patients.

Moreover, atezolizumab was FDA approved in October 2016 for metastatic NSCLC as second-line treatment, following platinum-based chemotherapy. The randomized phase II POPLAR study demonstrated a statistically significant survival benefit of atezolizumab versus docetaxel in NSCLC patients with medium and high PD-L1 expression (HR $=0.54 ; \mathrm{P}=0.014)$ (70). Similarly, the phase III OAK trial investigated atezolizumab versus docetaxel in the same setting (71). In the ITT population, the median OS was statistically improved for atezolizumab versus docetaxel [13.8 months (95\% CI: $11.8-15.7)$ vs. 9.6 months (95\% CI: 
8.6-11.2); HR 0.73 (95\% CI: 0.62-0.87); $\mathrm{P}=0.0003$ ]. The reported AEs were compatible with the POPLAR study.

Moreover, in December 2018, atezolizumab was approved by the FDA in combination with bevacizumab and standard chemotherapy for the first-line treatment of metastatic nonsquamous NSCLC, in the absence of epidermal growth factor receptor $(E G F R)$ mutations or anaplastic lymphoma kinase $(A L K)$ gene rearrangements (72). Finally, in March 2019, FDA granted first-line treatment of atezolizumab in combination with the standard carboplatin and etoposide for the extensive small-cell lung cancer (73).

In vivo studies demonstrated that durvalumab significantly inhibits the growth of human tumors in a novel xenograft model with co-implanted human T cells (74). Based on this preclinical evidence, durvalumab entered into clinical development. Indeed, patients with advanced urothelial bladder carcinoma, tolerated well durvalumab at a dose of $10 \mathrm{mg} / \mathrm{kg}$ every 2 weeks for up to a year or until disease progression, or unacceptable toxicities $(75,76)$. Overall, the demonstrated durvalumab tolerance outcome was similar to other PD-L1 inhibitors (75). Higher ORR was observed in patients with expression, as compared to lack of expression of PD-L1 (27.6\% versus 5.1\%, respectively) (76). In 2017, the FDA granted accelerated approval to durvalumab for the treatment of locally advanced or metastatic urothelial carcinoma. Furthermore, phase III PACIFIC trial compared consolidation treatment with durvalumab versus placebo in patients pre-treated with two or more cycles of platinumbased chemotherapy, concurrently with definitive radiation therapy. The 2-year OS rate in the durvalumab group was $66.3 \%$, compared with $55.6 \%$ in the placebo arm (77).

Avelumab induces tumor-directed antibody-dependent cell-mediated cytotoxicity in vitro (78). The dose-escalation phase I JAVELIN Solid Tumor study demonstrated that avelumab was generally well tolerated in patients with metastatic or locally advanced pre-treated solid tumors (79). Treatment-associated AEs are fatigue, influenza-like symptoms, fever, and chills. The MTD was $10 \mathrm{mg} / \mathrm{kg}$ every 2 weeks. However, atezolizumab did not induce a statistically significant prolongation of either OS or PFS in ovarian, gastric, and NSCLC versus chemotherapy (80-82).

\section{Toxicities in the checkpoint protein inhibitors- based combined treatment}

There is a growing interest in the incorporation of combination therapies in clinical practice, to be enhanced the antitumor effect. CTLA-4 and PD-1 receptors have distinct mechanisms of T-cell inhibition, which provide the rationale of the additive and/or synergistic activity of the dual checkpoint blockade (83). The development of resistance to immune checkpoint inhibitors may involve mechanisms of immune escape or tolerance (84). Based on that, targeting dual or multiple pathways may be an effective approach in treatment-resistant cancers.

Toxicities in combined strategies are more severe than those in single agents and depended on the combination patterns of different agents. The combination of ipilimumab and nivolumab has been approved for the treatment of metastatic melanoma (85). In an update of the CheckMate 067 trial, the rate of grade $3 / 4$ toxicities was $59 \%$ in the combination arm, versus $22 \%$ and $28 \%$ in the cohorts of single agents nivolumab and ipilimumab, respectively. Grade 3 diarrhea in the combination and nivolumab group was 9 and 3\% respectively, whereas colitis was the most frequent $\mathrm{AE}$ in the ipilimumab arm (7\%). Grade 4 lipasemia occurred in $5 \%$ of the combination group, and in $3 \%$ and $1 \%$ of nivolumab and ipilimumab cohorts, respectively (86). The increased incidence of AEs with combination therapy may also be related to dose and schedule. According to the CheckMate 511 trial, the regimen of nivolumab $3 \mathrm{mg} / \mathrm{kg}$ plus ipilimumab $1 \mathrm{mg} / \mathrm{kg}$ (NIVO3 + IPI1) is better tolerated as compared to the approved treatment (NIVO1 + IPI3). Indeed, the incidence of treatment-mediated grade 3-5 AEs was 34 versus $48 \%$, in favor of NIVO3 + IPI1 (P=0.006). In terms of treatment efficacy, response rates and PFS did not differ whereas, OS was not reached in either group (87).

The combination of ipilimumab and pembrolizumab seems to be well tolerated. Preliminary results of the phase Ib Keynote 029 study demonstrated $42 \%$ general incidence of grade 3/4 AEs. The reported lipasemia and diarrhea of grade $3 / 4$ were 14 and $<1 \%$, respectively (88).

The efficacy and safety of the combination of immunotherapy and targeted therapy are currently under investigation. In a phase I study, the tolerance of ipilimumab/vemurafenib doublet was problematic (89). Liver biochemistry was impaired in four out of six patients treated with a full dose of either agent and in two out of four of those treated with dose modification. In the sequential phase II study (NCT01673854), patients were treated with vemurafenib for 6 weeks and then switched to ipilimumab at the dose of $10 \mathrm{mg} / \mathrm{kg}$. The incidence of grade $3 / 4$ skin, GI, and hepatobiliary AEs was 32.6\%, 21.7\%, and $4.3 \%$, respectively (90).

The combination of an anti-PD-1 or anti-PD-L 1 antibody with targeted therapy seems to be better tolerated 
Table 1 Incidence of adverse events in combination studies with anti-PD-1/anti-PD-L1 agents

\begin{tabular}{|c|c|c|c|c|c|c|}
\hline Ref. & Trial & Treatment & $\begin{array}{l}\text { Number } \\
\text { of patients }\end{array}$ & AEs (\%) & Grade $3 / 4$ AEs (\%) & $\begin{array}{c}\text { Treatment } \\
\text { discontinuation } \\
\text { due to AEs (\%) }\end{array}$ \\
\hline (88) & Phase II & pembro + ipi & 153 & 58\%. Diarrhea: 46; Pruritus: 39; Rash: 39 & $42 \%$ & $20 \%$ \\
\hline \multirow[t]{3}{*}{ (91) } & Phase I & $M+T \pm D$ & 50 & $\begin{array}{c}\text { Cohort } A(M+T+D): \\
\text { Pyrexia: } 63 \% \text {; Fatigue: } 54 \%\end{array}$ & $4 \%$ & $4 \%$ \\
\hline & & & & Cohort B $(M+T)$ : Diarrhea: 30\%; Rash: $25 \%$ & & \\
\hline & & & & Cohort C $(T \rightarrow M)$ : Vomiting: $67 \%$ & & \\
\hline (92) & Phase I/II & pembro $+\mathrm{D}+\mathrm{T}$ & 15 & NR & $67 \%$ & $33 \%$ \\
\hline (93) & Phase lb & $A+V+$ cobi & 11 & $20 \%$ (hypertransaminasaemia) & $\begin{array}{l}\text { 40\% elevation of CPK; } \\
\text { sepsis; diarrhea and } \\
\text { hypertransaminasaemia }\end{array}$ & $9 \%$ \\
\hline
\end{tabular}

anti-PD-1, anti-programmed death antigen-1; anti-PD-L1, anti-programmed death antigen-ligand-1; nivo, nivolumab; ipi, ipilimumab; pembro, pembrolizumab; M, durvalumab; T, trametinib; D, dabrafenib; pts, patients; DLT, dose-limiting toxicity; NR, not reported; A, atezolizumab; V, vemurafenib; cobi, cobimetinib; CPK, creatine-phosphokinase.

than with CTLA-4 inhibitor (91-93). NCT02027961 is evaluating durvalumab in combination with dabrafenib plus trametinib, or trametinib alone in metastatic melanoma. Patients were randomized by BRAF status to one of three dose-escalation cohorts (durvalumab + dabrafenib + trametinib, versus durvalumab + trametinib, versus sequential trametinib followed by durvalumab). No MTD was identified, whereas the most common gastrointestinal AEs were diarrhea in cohort B (30\%), and vomiting in cohort $\mathrm{C}(67 \%)$. Based on that, the combination of durvalumab and trametinib with or without dabrafenib at full doses can be considered in patients with either BRAFmutated or wild type melanoma (91).

KEYNOTE-022 (NCT02130466) is a phase I/II study that investigated pembrolizumab in combination with dabrafenib and trametinib in the first-line setting, in patients with melanoma harboring BRAF-V600 mutation. Ten out of 15 patients (67\%) experienced grade $3 / 4$ treatment-induced AEs, including 2 cases with a reversible increase of aminotransferases. The recommended phase II MTD is pembrolizumab $2 \mathrm{mg} / \mathrm{kg}$ every 3 weeks, combined with dabrafenib at $150 \mathrm{mg}$ twice daily and trametinib $2 \mathrm{mg}$ once daily (92).

Preliminary data of atezolizumab combined with cobimetinib and vemurafenib demonstrated manageable toxicities in patients with metastatic melanoma bearing BRAF-V600 mutations (93). More than $20 \%$ of patients experienced all-grade AEs, including nausea, elevated aminotransferases and bilirubin, and mucositis. Among the patients treated with the combination, $40 \%$ experienced grade 3/4 AEs, which were atezolizumab-associated in $27 \%$ out of them. Among 14 enrolled patients, only one discontinued due to elevated alanine aminotransferase (ALT)/aspartate aminotransferase (AST) ratio. The ongoing phase III TRILOGY study (NCT02908672) evaluates cobimetinib and vemurafenib, combined or not with atezolizumab for treatment-naïve patients with BRAF-V600 mutated metastatic melanoma (94).

The combination of checkpoint blockade immunotherapy and radiation could also be toxic. Within this context are included increased incidence of pneumonitis, colitis, and hypophysitis with lung, bowel, and central nervous system irradiation, respectively (95).

The increased incidence of AEs with combination immunotherapies is depicted in Table 1 .

\section{Organ-special toxicities of checkpoint protein inhibitors}

Approximately, over $30 \%$ of the patients treated with immunotherapy, mainly monoclonal anti-CTLA-4 IgG1 and anti-PD1 IgG4 antibodies, experienced AEs related to the digestive system (96). The incidence of grade $3 / 4$ immunemediated diarrhea and colitis is approximately $5 \%$ with ipilimumab and 1-3\% with anti-PD-1/PD-L1 antibodies. Colitis is usually occurred within the first 6 weeks, following 
commencement of immune checkpoint inhibitor, somewhat later than dermatological AEs; nevertheless, it can also be presented anytime through the treatment course (97). Bowel perforation associated with colitis has been reported in the initial studies with ipilimumab, rather than with anti-PD-1/ PD-L1 therapy (98-100).

Immune cell infiltration of bowel mucosa is correlated with gastrointestinal toxicity and $\mathrm{T}$-cell diversity predicts AEs. There is not mature evidence to correlate potential risk factors with the development of gastrointestinal AEs; nevertheless, personal and family history of autoimmune diseases, tumoral infiltration, opportunistic pathogens, comedications, and professional exposures are considered as risk factors. Leptin stimulates the production of IL-1, IL-6, IL-12, and tumor necrosis factor- $\alpha$ (TNF- $\alpha$ ), promotes $T$-cell proliferation, and inhibits regulatory $\mathrm{T}$-cell proliferation. The successful management of some AEs with anti-TNF treatment supports that inflammatory cytokines, related to the adipose tissue inflammation are involved in the development of gastrointestinal AEs.

The gold standard to diagnose patients with lower and upper gastrointestinal symptoms is the colonoscopy and gastroscopy, respectively (101). Histological specimens should be taken throughout the colon, even if the mucosa is normal, whilst immunohistochemical staining is required as the infection by cytomegalovirus should be a consideration in the differential diagnosis of colitis. Endoscopic appearance is compatible either with chronic idiopathic inflammatory bowel disease and acute, infectious, or drugrelated colitis (102). Typical findings include inflammatory changes, such as neutrophils, lymphocytes, plasma cells, and eosinophils, loss of vascularity, and ulcerations (103). They can also be detected in foci of neutrophilic cryptitis, and crypt abscess (104). Beyond the colon, histopathological abnormalities may also be detected in the duodenum, stomach, and/or small bowel (105). In a case series of 39 patients treated with anti-CTLA-4, the most frequently described endoscopic lesions were ulcer (79\%), erosion (13\%), and erythema ( $8 \%)(106)$. The rectum and/or sigmoid colon were affected in $97 \%$ of cases, whilst $66 \%$ of patients developed extensive colitis. In another series, among 20 patients with anti-PD1-induced diarrhea, 12 had abnormal colonoscopies. The descending colon was mostly affected $(83 \%)$ with a patchy, rather than a continuous pattern in approximately $73 \%$ of cases (107).

Radiological appearance is wildly fluctuated, according to the severity of AEs. The most common diffuse colitis is characterized by mesenteric vessel engorgement, and a segmental counterpart with moderate bowel wall thickening, fluid-filled colonic distention, and pericolonic fat stranding in a background of diverticulosis (108).

The differential diagnosis of diarrhea and colitis includes tumor progression, the development of inflammatory bowel disease and infectious causes, based on the identification of clostridium difficile, cytomegalovirus, and parasites $(97,109)$. The correlation with the clinical history is essential for the differential diagnosis. Inflammatory markers such as fecal leukocytes/lactoferrin and fecal calprotectin may clarify the inflammatory process underlying the diarrhea. Overall, the main laboratory abnormalities are nonspecific and include anemia, increased C-reactive protein, and hypoalbuminemia. The screening strategy should incorporate assessment for tuberculosis, human immunodeficiency virus and hepatitis A, $\mathrm{B}$, and $\mathrm{C}$.

Patients treated with ipilimumab $(43,110-112)$, and antiPD-1/PD-L1 agents (98-100), experience hepatic toxicity in approximately $10 \%$ and $5 \%$, respectively. Patients with solid tumors from nine randomized trials were included in a meta-analysis, which showed that treatment with PD-1 inhibitors increased the risk of all but high-grade hepatic AEs, versus either chemotherapy or everolimus. The median time to the occurrence of hepatitis depends on the malignant disease and the immune checkpoint inhibitor (113-116). The peak toxicity occurs within 8 to 12 weeks after initiation of ipilimumab (99,100,117), whilst anti-PD1/ PD-L1 induced hepatitis may be correlated with later-onset symptoms, even 34 weeks since treatment's initiation (118). Overall, it is a heterogeneous clinical entity that often manifests as an asymptomatic increase of aminotransferases and/or bilirubin. However, fatigue, fever, and jaundice have also been reported (113), whilst fulminant hepatic failure is rare (119). Immune checkpoint inhibitors are not metabolized by the liver and as such, baseline liver impairment is not a contraindication for treatment initiation (120). There is a lack of predictive and/or prognostic biomarkers for immune-related hepatitis (121).

From the histopathological point of view have been described findings of panlobular hepatitis, biliary ducts or perivenular infiltrates (117), whilst rarely have been reported fibrin ring granulomas (122). In anti-PD1 induced hepatitis, the appearance is more heterogeneous with lobular and periportal activity (114). Imaging features of immune-related hepatitis are not pathognomonic; nevertheless, more severe appearance could be characterized by hepatomegaly, periportal edema, and lymphadenopathy, as well as attenuated liver parenchyma. Moreover, 
radiological features compatible with cholangitis have been described in patients treated with nivolumab $(123,124)$.

The differential diagnosis of immune-related hepatotoxicity requires a thorough history and physical exam, accompanied by laboratory and histological assessment (125). It includes recurrent liver disease, viral hepatitis, another drug-induced toxic reaction, alcoholic liver disease, cholangitis, and portal vein thrombosis $(64,126)$. Patients with autoimmune and drug-induced hepatitis may have features of elevated aminotransferases, eosinophilia, and hypergammaglobulinemia. However, the presence of plasma cells is more typical in autoimmune hepatitis, whilst neutrophils prevail in drug-mediated hepatitis. Furthermore, cirrhosis or rosette formation mostly characterize autoimmune, rather than drug-induced hepatitis (127). Hepatic AEs can also induce rapid fibrosis. Finally, they are primarily characterized by lobular hepatitis with $\mathrm{CD} 3+$ or CD8+ lymphocyte infiltration, rather than with CD20+ lymphocytes. There have not been found histological differences between anti-PD-1/PD-L1 and anti-CTLA-4 agents so far.

Acute pancreatitis has been rarely reported (128). However, the asymptomatic increase of lipase and amylase are more frequent, in the absence of clinical or radiological features of pancreatitis (129). This biochemical derange does not have any clinical impact and immune checkpoint inhibitor could be continued. In contrast, if there is clinical or radiological evidence of pancreatitis, treatment should be withheld until resolution.

The autoimmune reactions mediated by immune checkpoint inhibitors seem to be related to the targeted pathways. Indeed, due to the presence of CTLA-4 in the hypophysis, patients treated with anti-CTLA-4 are susceptible to hypophysitis, which is not the case in those treated with anti-PD1. Similarly, the predominant AEs of anti-CTLA-4 are colitis and hypophysitis, whilst antiPD1/PD-L1 can induce type I diabetes, hypothyroidism, pneumonitis, and myocarditis. Finally, autoimmune syndromes could be a consequence of revealing preexisting conditions. However, analysis of pre-existing autoantibodies and single-nucleotide polymorphisms associated with autoimmune disease has not proved useful in the identification of patients at risk for AEs.

\section{Management of toxicities}

The education of patients is crucial for the optimal management of AEs. The early recognition of symptoms leads to prompt diagnosis and early commencement of specific treatment. Algorithms with well-described supportive measures are mostly, empiric and data are extrapolated from inflammatory bowel disorders. Diagnosis of an immune-mediated AEs may be challenging, mainly on the absence of specific antibodies in the serum. In this scenario, a biopsy is extremely important for the establishment of the diagnosis. Gold standard treatment is considered the initiation of immunosuppressants, usually with corticosteroids. For those, to whom the initial immune-modulators are ineffective, secondary immunosuppressive agents, such as infliximab or mycophenolate, may be recommended. Table 2 includes the indicated for each significant toxicity treatment.

Among commonly used corticosteroids, oral prednisone 1 $\mathrm{mg} / \mathrm{kg}$ daily is recommended for moderate toxicities, whilst intravenous methylprednisolone $2-4 \mathrm{mg} / \mathrm{kg}$ daily for severe events. They should be weaned slowly, over a minimum of 4 weeks (130). For prolonged exposure to corticosteroids or other immunosuppressive drugs, prophylactic antifungal and antibiotic agents should be considered, due to the risk of opportunistic infections. Trimethoprim/sulfamethoxazole once daily or three times weekly (160/800 mg combination strength) is widely recommended (131). Blood glucose levels should be monitored during the treatment course. Corticosteroid management should be individualized based on patients' medical history, co-morbidities, oncological background, previous AEs, and administered agent.

Infliximab represents a monoclonal antibody against the inflammatory cytokine TNF- $\alpha$. It has shown apparent early efficacy in the treatment of gastrointestinal AEs at the dose of $5 \mathrm{mg} / \mathrm{kg}$ (132); nevertheless, the effect of infliximab on tumor progression is uncertain (133). Some data are suggestive of increased risk of developing new cancers with TNF inhibitors treatment (134).

Grade 1 diarrhea can be managed symptomatically with orally given loperamide, rehydration, and electrolytes replacement. In case that symptoms last longer than 2 weeks (grade 2 diarrhea), an endoscopy is indicated, whereas colonic biopsies are suggested for bacteriological and pathological analyses. Treatment should be commenced with oral prednisone $0.5-1 \mathrm{mg} / \mathrm{kg}$ or equivalent, after eliminating an infectious etiology. When symptoms are resolved, the immunotherapy treatment can be restarted with dose modification (135). In grade 3/4 diarrhea, an endoscopic assessment is mandatory, preferably with a total colonoscopy and an upper endoscopy $(106,136)$. In the presence of fever or severe abdominal pain, an 
Table 2 Management of toxicities of immune checkpoint inhibitors

\begin{tabular}{|c|c|c|c|c|}
\hline $\begin{array}{l}\text { Adverse } \\
\text { event }\end{array}$ & Grade & Clinical status & Management of AEs & Immunotherapy management \\
\hline \multirow[t]{3}{*}{ Diarrhea } & 1 & $\begin{array}{l}\text { Increase of }<4 \text { stools } \\
\text { daily over baseline }\end{array}$ & $\begin{array}{l}\text { Stool MCS; Rehydration; Electrolyte replacements; } \\
\text { Loperamide }\end{array}$ & No delay of $\mathrm{ICl}$ \\
\hline & 2 & $\begin{array}{l}\text { Increase of } 4-6 \text { stools } \\
\text { daily over baseline }\end{array}$ & $\begin{array}{l}\text { Stool MCS; Oral corticosteroids }(0.5-1 \mathrm{mg} / \mathrm{kg} \text { daily); } \\
\text { Restarting } \mathrm{ICl} \text { upon resolution of symptoms }\end{array}$ & Delay of ICI \\
\hline & 4 & $\begin{array}{l}\text { Life-threatening } \\
\text { consequences }\end{array}$ & $\begin{array}{l}\text { Consideration of mycophenolate mofetil in severe and } \\
\text { refractory cases; Colonoscopy in either colitis suspected } \\
\text { or persistent diarrhea despite corticosteroids }\end{array}$ & \\
\hline Colitis & 3 & $\begin{array}{l}\text { Severe abdominal } \\
\text { pain; Change in } \\
\text { bowel habits; } \\
\text { Peritoneal signs }\end{array}$ & $\begin{array}{l}\text { Intravenous methylprednisone ( } 1-2 \mathrm{mg} / \mathrm{kg} \text { daily) for } 3 \text { days, } \\
\text { followed by oral prednisolone ( } 1-2 \mathrm{mg} / \mathrm{kg} \text { daily); Tapering } \\
\text { off corticosteroids over } 4 \text { weeks; If symptoms persist, } \\
\text { a single dose of infliximab ( } 5 \mathrm{mg} / \mathrm{kg}) \text {, unless there is a } \\
\text { contraindication; Gastroenterology referral; Consideration } \\
\text { of colonoscopy with biopsies }\end{array}$ & $\begin{array}{l}\text { Withholding of } \mathrm{ICl} \text {; Restarting } \\
\mathrm{ICl} \text { upon improvement to } \\
\text { grade } 0-1 \text { within } 12 \text { weeks }\end{array}$ \\
\hline \multirow{2}{*}{ Hepatitis } & 2 & $\begin{array}{l}\text { AST/ALT }>3-5 \times \text { ULN } \\
\text { or total bilirubin }>1.5- \\
3 \times \text { ULN }\end{array}$ & $\begin{array}{l}\text { Conditions that should be ruled out: viral hepatitis, } \\
\text { autoimmune disease, biliary obstruction, new metastasis, } \\
\text { or thrombosis; LFTs every } 3 \text { days; Consideration of liver } \\
\text { biopsy; Oral prednisolone or equivalent ( } 1 \mathrm{mg} / \mathrm{kg} \text { daily); } \\
\text { Wean steroids when hepatitis resolves to grade } 0\end{array}$ & $\begin{array}{l}\text { Withholding of } \mathrm{ICl} \text {; Restarting } \\
\mathrm{ICI} \text { upon improvement to } \\
\text { grade } 0-1 \text { within } 12 \text { weeks }\end{array}$ \\
\hline & 3 & $\begin{array}{l}\text { AST/ALT }>5 \times \text { ULN } \\
\text { or total bilirubin }>3 \times \\
\text { ULN }\end{array}$ & $\begin{array}{l}\text { Conditions that should be ruled out: viral hepatitis, } \\
\text { autoimmune disease, biliary obstruction, new metastasis, } \\
\text { or thrombosis; LFTs daily; Intravenous methylprednisone } \\
\text { (1-2 mg/kg daily) for } 3 \text { days, followed by oral prednisolone } \\
\text { (1-2 mg/kg daily) or equivalent; Tapering off corticosteroids } \\
\text { over } 4 \text { weeks; If symptoms persist, consideration of } \\
\text { oral mycophenolate mofetil ( } 500-1,000 \text { mg twice daily); } \\
\text { Gastroenterology referral; Consideration of liver biopsy }\end{array}$ & $\begin{array}{l}\text { Permanently discontinuation } \\
\text { of } \mathrm{ICI}\end{array}$ \\
\hline
\end{tabular}

AEs, adverse events; MCS, microscopy; ICI, immune checkpoint inhibitor; CRP, C-reactive protein; ESR, erythrocyte sedimentation rate; CTLA-4, cytotoxic T-lymphocyte antigen 4; PD-1, programmed cell death 1; AST, aspartate aminotransferase; ALT, alanine aminotransferase; ULN, upper limit of normal; LFTs, liver function tests. 
abdominal computed tomography is necessary to rule out bowel perforation or toxic megacolon. Intravenous methylprednisolone $1-2 \mathrm{mg} / \mathrm{kg}$ daily represent the initial treatment, followed by corticosteroids orally (135). Patients who do not respond after 3 days of treatment should commence infliximab. In cases of persisting symptoms, it is recommended to be repeated the dose of infliximab after 2 weeks $(98,99)$. In a study, infliximab was administered to $13 \%$ of patients treated with the combination of anti-PD1 and anti-CTLA-4, compared with $9 \%$ of those who were on single-agent anti-CTLA-4 (137). Mycophenolate mofetil can also be considered in severe and refractory cases (97).

In persistent grade 2-4 immune-mediated colitis is recommended treatment with methylprednisolone at the dose of $1-2 \mathrm{mg} / \mathrm{kg}$ daily (138). Cases of microscopic colitis have also been described in patients treated with anti-PD-1, and effective therapy with budesonide $9 \mathrm{mg}$ daily has been reported (136). However, this agent is no longer prophylactically recommended (139). Rechallenging immune checkpoint inhibitor after severe colitis can be considered in selected patients. Single-agent anti-PD-1 may be a reasonable therapeutic maneuver when combined therapy is withheld due to severe colitis (140).

Severe or life-threatening colitis, along with signs and symptoms of perforation, ileus, toxic megacolon, bleeding or even fever are serious AEs. Although perforation of the colon occurs in less than $<1 \%$ of cases, surgery could be required with a subtotal and not segmental colectomy, as anti-CTLA-4-mediated enterocolitis potentially affects the entire colon $(141,142)$.

Treatment-mediated hepatic toxicity is classified in accordance to the pattern of liver transaminases increasement. This pattern is defined by either the elevation of ALT or alkaline phosphatase (ALP) alone above a specific threshold, or by the ratio of ALT to ALP levels $\{\mathrm{R}$ value $=[$ ALT/upper limit of normal $(\mathrm{ULN})] /[\mathrm{ALP} / \mathrm{ULN}]\}$. The recognized patterns are the hepatocellular (ALT $\geq 5$ fold above ULN or $\mathrm{R}>5$ ), the mixed ( $>2$ to $<5$ ), and the cholestatic (ALP $\geq 2$-fold above ULN or $\mathrm{R}<2$ ), respectively. It seems that immune checkpoint inhibitors-induced hepatic toxicity is heterogeneous (cytolytic, mixed or cholestatic). Nevertheless, the frequency of cholestasis is overall lower. Beyond the exact type of immunotherapy, liver toxicity depends on dose and baseline liver function. The Common Terminology Criteria for Adverse Events developed by the National Cancer Institute are used to grade toxicity. Within this context, acute hepatitis is considered severe, when INR is $\geq 1.5$, and fulminant in case of concurrent impaired coagulation and hepatic encephalopathy. Technically, patients with grade 1 hepatotoxicity may continue treatment with immune checkpoint inhibitors, monitoring the liver biochemistry. For grade 2 AEs are recommended systemic treatment delays, identification of other causes of hepatitis, and oral prednisone $(1 \mathrm{mg} / \mathrm{kg}$ daily) in persistent cases $(143,144)$. In cases of severe hepatotoxicity, it is clearly indicated discontinuation of immunotherapy permanently, accompanied by high-dose intravenous glucocorticosteroids [1-2 mg/kg (143), or even 2-4 mg/kg daily (145)], followed by an oral steroid tapered over not less than a month. In refractory cases, the use of other suppressive agents such as mycophenolate mofetil (500-1,000 $\mathrm{mg}$ twice daily), tacrolimus or cyclophosphamide has been suggested, without strong evidence. Furthermore, budesonide may have a role in view of avoiding any kind of systemic toxicities induced by corticosteroids and immunosuppressive drugs $(141,146)$. Finally, infliximab may impaire liver function and as such should be avoided in that clinical scenario.

The effectiveness of combining radiotherapy with immune checkpoint inhibitors has been shown in many models, but the question of the optimal timing of these treatment combinations remains unanswered. Interactions between myeloid cells and antitumor cytotoxic $\mathrm{T}$ cells within tumors are complex. The data available to date seem to justify either simultaneous or delayed administration of checkpoint inhibitors after radiotherapy so that newly recruited $T$ cells can destroy tumor cells, both at the primary site and systemically after being presented with novel tumor antigens. The immune checkpoint inhibitors maintenance strategy paradigm increases exposure to effective therapies especially through a switching approach in patients who achieve disease control after front-line chemotherapy. The available biological and clinical data support this hypothesis and required further validation in phase III trials. The IMpower133 trial in the first-line treatment of extensive small-cell lung cancer demonstrated that the incorporation of atezolizumab to carboplatin and etoposide led to statistically significant prolongation of OS and PFS (73).

\section{Conclusions and future directions}

Immune-related AEs are fairly common but rarely severe. Beyond other toxicities, these drugs may cause inflammation of the luminal gastrointestinal tract and liver. The frequency and severity of the AEs are more profound in the combined strategies than in either single immune checkpoint inhibitor. 
The toxicities may last for several months, which necessitate constant vigilance and prompt treatment. Until prospective clinical data will be available, evidence for the diagnosis and management of the immune checkpoint inhibitors mediated AEs is extrapolated from other inflammatory disorders. he question of the long term consequences of the AEs will surely be debated in the near future, as immune checkpoint inhibitors can induce some durable remissions, and have now been incorporated in the adjuvant setting. A better understanding of the role of genetics and the microbiome in the development of AEs is of major importance, as there is a lack of predictive biomarkers of immunotherapy toxicity across multiple tumor types. Advanced computing technologies and bioinformatics-based models can also be innovated to identify drug interactions. The optimal selection of cancer patients more likely to benefit from immunotherapy represents an additional challenge. Timely initiation of steroids and other immunosuppressive agents has benefits that are several-fold.

\section{Acknowledgments}

The authors acknowledge support from the King's College London, School of Cancer \& Pharmaceutical Sciences, London UK, and the Research and Innovation department of Medway NHS Foundation Trust, Kent, UK.

Funding: None.

\section{Footnote}

Reporting Checklist: The authors have completed the Narrative Review reporting checklist. Available at http:// dx.doi.org/10.21037/atm-20-7361

Conflicts of Interest: All authors have completed the ICMJE uniform disclosure form (available at http://dx.doi. org/10.21037/atm-20-7361). SB serves as an unpaid editorial board member of Annals of Translational Medicine from Nov 2019 to Oct 2021. The other authors have no conflicts of interest to declare.

Ethical Statement: The authors are accountable for all aspects of the work in ensuring that questions related to the accuracy or integrity of any part of the work are appropriately investigated and resolved.

Open Access Statement: This is an Open Access article distributed in accordance with the Creative Commons
Attribution-NonCommercial-NoDerivs 4.0 International License (CC BY-NC-ND 4.0), which permits the noncommercial replication and distribution of the article with the strict proviso that no changes or edits are made and the original work is properly cited (including links to both the formal publication through the relevant DOI and the license). See: https://creativecommons.org/licenses/by-nc-nd/4.0/.

\section{References}

1. Mellman I, Coukos G, Dranoff G. Cancer immunotherapy comes of age. Nature 2011;480:480-9.

2. Peggs KS, Quezada SA, Allison JP. Cell intrinsic mechanisms of T-cell inhibition and application to cancer therapy. Immunol Rev 2008;224:141-65.

3. Brahmer JR, Tykodi SS, Chow LQM, et al. Safety and activity of anti-PD-L1 antibody in patients with advanced cancer. N Engl J Med 2012;366:2455-65.

4. Fife BT, Bluestone JA. Control of peripheral T-cell tolerance and autoimmunity via the CTLA- 4 and PD-1 pathways. Immunol Rev 2008;224:166-82.

5. Lu J, Lee-Gabel L, Nadeau MC, et al. Clinical evaluation of compounds targeting PD-1/PD-L1 pathway for cancer immunotherapy. J Oncol Pharm Pract 2015;21:451-67.

6. Weber JS, Hodi FS, Wolchok JD, et al. Safety Profile of Nivolumab Monotherapy: A Pooled Analysis of Patients With Advanced Melanoma. J Clin Oncol 2017;35:785-92.

7. Kantoff PW, Higano CS, Shore ND, et al. IMPACT Study Investigators. Sipuleucel-T immunotherapy for castration-resistant prostate cancer. N Engl J Med 2010;363:411-22.

8. Anassi E, Ndefo UA. Sipuleucel-T (provenge) injection: the first immunotherapy agent (vaccine) for hormonerefractory prostate cancer. P T 2011;36:197-202.

9. Kaufman HL. Vaccines for melanoma and renal cell carcinoma. Semin Oncol 2012;39:263-75.

10. Dranoff G, Jaffee E, Lazenby A, et al. Vaccination with irradiated tumor cells engineered to secrete murine granulocyte-macrophage colony-stimulating factor stimulates potent, specific, and long-lasting anti-tumor immunity. Proc Natl Acad Sci U S A 1993;90:3539-43.

11. Armstrong CA, Botella R, Galloway TH, et al. Antitumor effects of granulocyte-macrophage colony-stimulating factor production by melanoma cells. Cancer Res 1996;56:2191-8.

12. Small EJ, Sacks N, Nemunaitis J, et al. Granulocyte macrophage colony-stimulating factor--secreting allogeneic cellular immunotherapy for hormone-refractory 
prostate cancer. Clin Cancer Res 2007;13:3883-91.

13. Sanda MG, Ayyagari SR, Jaffee EM, et al. Demonstration of a rational strategy for human prostate cancer gene therapy. J Urol 1994;151:622-8.

14. Dunussi-Joannopoulos K, Dranoff G, Weinstein HJ, et al. Gene immunotherapy in murine acute myeloid leukemia: granulocyte-macrophage colony-stimulating factor tumor cell vaccines elicit more potent antitumor immunity compared with B7 family and other cytokine vaccines. Blood 1998;91:222-30.

15. Lipson EJ, Sharfman WH, Chen S, et al. Safety and immunologic correlates of Melanoma GVAX, a GM-CSF secreting allogeneic melanoma cell vaccine administered in the adjuvant setting. J Transl Med 2015;13:214.

16. Laheru D, Lutz E, Burke J, et al. Allogeneic granulocyte macrophage colony-stimulating factor-secreting tumor immunotherapy alone or in sequence with cyclophosphamide for metastatic pancreatic cancer: a pilot study of safety, feasibility, and immune activation. Clin Cancer Res 2008;14:1455-63.

17. Salgia R, Lynch T, Skarin A, et al. Vaccination with irradiated autologous tumor cells engineered to secrete granulocyte-macrophage colony-stimulating factor augments antitumor immunity in some patients with metastatic non-small-cell lung carcinoma. J Clin Oncol 2003;21:624-30.

18. Berd D, Sato T, Cohn H, et al. Treatment of metastatic melanoma with autologous, hapten-modified melanoma vaccine: regression of pulmonary metastases. Int J Cancer 2001;94:531-9.

19. Banchereau J, Pascual V, O'Garra A. From IL-2 to IL-37: the expanding spectrum of anti-inflammatory cytokines. Nat Immunol 2012;13:925-31.

20. Tedgui A, Mallat Z. Cytokines in atherosclerosis: pathogenic and regulatory pathways. Physiol Rev 2006;86:515-81.

21. Tarhini AA, Gogas H, Kirkwood JM. IFN- $\alpha$ in the treatment of melanoma. J Immunol 2012;189:3789-93.

22. Weiss K. Safety profile of interferon-alpha therapy. Semin Oncol 1998;25:9-13.

23. Cole BF, Gelber RD, Kirkwood JM, et al. Quality-of-lifeadjusted survival analysis of interferon alfa-2b adjuvant treatment of high-risk resected cutaneous melanoma: an Eastern Cooperative Oncology Group study. J Clin Oncol 1996;14:2666-73.

24. Creagan ET, Ahmann DL, Frytak S, et al. Phase II trials of recombinant leukocyte A interferon in disseminated malignant melanoma: results in 96 patients. Cancer Treat
Rep 1986;70:619-24.

25. Coppin C, Porzsolt F, Awa A, et al. Immunotherapy for advanced renal cell cancer. Cochrane Database Syst Rev 2005;1:CD001425.

26. Motzer RJ, Hutson TE, Tomczak P, et al. Overall survival and updated results for sunitinib compared with interferon alfa in patients with metastatic renal cell carcinoma. J Clin Oncol 2009;27:3584-90.

27. Schuchter LM. Adjuvant interferon therapy for melanoma: high-dose, low-dose, no dose, which dose? J Clin Oncol 2004;22:7-10

28. Jones TH, Wadler S, Hupart KH. Endocrine-mediated mechanisms of fatigue during treatment with interferonalpha. Semin Oncol 1998;25:54-63.

29. Kirkwood JM, Bender C, Agarwala S, et al. Mechanisms and management of toxicities associated with high-dose interferon alfa-2b therapy. J Clin Oncol 2002;20:3703-18.

30. Goldstein D, Laszlo J. The role of interferon in cancer therapy: a current perspective. CA Cancer J Clin 1988;38:258-77.

31. Schwartzentruber DJ. Guidelines for the safe administration of high-dose interleukin-2. J Immunother 2001;24:287-93.

32. Antony GK, Dudek AZ. Interleukin 2 in cancer therapy. Curr Med Chem 2010;17:3297-3302.

33. June CH, Riddell SR, Schumacher TN. Adoptive cellular therapy: a race to the finish line. Sci Transl Med 2015;7:280ps7.

34. Dudley ME, Wunderlich JR, Robbins PF, et al. Cancer regression and autoimmunity in patients after clonal repopulation with antitumor lymphocytes. Science 2002;298:850-4.

35. Dudley ME, Yang JC, Sherry R, et al. Adoptive cell therapy for patients with metastatic melanoma: evaluation of intensive myeloablative chemoradiation preparative regimens. J Clin Oncol 2008;26:5233-9.

36. Eshhar Z, Waks T, Gross G, et al. Specific activation and targeting of cytotoxic lymphocytes through chimeric single chains consisting of antibody-binding domains and the gamma or zeta subunits of the immunoglobulin and T-cell receptors. Proc Natl Acad Sci U S A 1993;90:720-4.

37. Krause A, Guo HF, Latouche JB, et al. Antigendependent CD28 signaling selectively enhances survival and proliferation in genetically modified activated human primary T lymphocytes. J Exp Med 1998;188:619-26.

38. Kalos M, Levine BL, Porter DL, et al. T cells with chimeric antigen receptors have potent antitumor effects and can establish memory in patients with advanced 
leukemia. Sci Transl Med 2011;3:95ra73.

39. Porter DL, Levine BL, Kalos M, et al. Chimeric antigen receptor-modified $\mathrm{T}$ cells in chronic lymphoid leukemia. N Engl J Med 2011;365:725-33.

40. Maughan BL, Bailey E, Gill DM, et al. Incidence of Immune-Related Adverse Events with Program Death Receptor-1- and Program Death Receptor-1 LigandDirected Therapies in Genitourinary Cancers. Front Oncol 2017;7:56.

41. Linsley PS, Greene JL, Brady W, et al. Human B7-1 (CD80) and B7-2 (CD86) bind with similar avidities but distinct kinetics to CD28 and CTLA-4 receptors. Immunity 1994;1:793-801.

42. Attia P, Phan GQ, Maker AV, et al. Autoimmunity correlates with tumor regression in patients with metastatic melanoma treated with anti-cytotoxic T-lymphocyte antigen-4. J Clin Oncol 2005;23:6043-53.

43. Hodi FS, O'Day SJ, McDermott DF, et al. Improved survival with ipilimumab in patients with metastatic melanoma. N Engl J Med 2010;363:711-23.

44. Yuan J, Adamow M, Ginsberg BA, et al. Integrated NYESO-1 antibody and CD8+ T-cell responses correlate with clinical benefit in advanced melanoma patients treated with ipilimumab. Proc Natl Acad Sci U S A 2011;108:16723-8.

45. Ribas A, Kefford R, Marshall MA, et al. Phase III randomized clinical trial comparing tremelimumab with standard-of-care chemotherapy in patients with advanced melanoma. J Clin Oncol 2013;31:616-22.

46. Keir ME, Butte MJ, Freeman GJ, et al. PD-1 and its ligands in tolerance and immunity. Annu Rev Immunol 2008;26:677-704.

47. Ishida Y, Agata Y, Shibahara K, et al. Induced expression of PD-1, a novel member of the immunoglobulin gene superfamily, upon programmed cell death. EMBO J 1992;11:3887-95.

48. Wang L, Pino-Lagos K, de Vries VC, et al. Programmed death 1 ligand signaling regulates the generation of adaptive Foxp3+CD4+ regulatory T cells. Proc Natl Acad Sci U S A 2008;105:9331-6.

49. Francisco LM, Salinas VH, Brown KE, et al. PD-L1 regulates the development, maintenance, and function of induced regulatory T cells. J Exp Med 2009;206:3015-29.

50. Borghaei H, Paz-Ares L, Horn L, et al. Nivolumab versus Docetaxel in Advanced Nonsquamous Non-Small-Cell Lung Cancer. N Engl J Med 2015;373:1627-39.

51. Brahmer J, Reckamp KL, Baas P, et al. Nivolumab versus Docetaxel in Advanced Squamous-Cell Non-Small-Cell Lung Cancer. N Engl J Med 2015;373:123-35.
52. Vokes EE, Ready N, Felip E, et al. Nivolumab versus docetaxel in previously treated advanced non-small-cell lung cancer (CheckMate 017 and CheckMate 057): 3-year update and outcomes in patients with liver metastases. Ann Oncol 2018;29:959-65.

53. Motzer RJ, Escudier B, McDermott DF, et al. CheckMate 025 Investigators. Nivolumab versus Everolimus in Advanced Renal-Cell Carcinoma. N Engl J Med 2015;373:1803-13.

54. Patnaik A, Kang SP, Rasco D, et al. Phase I Study of Pembrolizumab (MK-3475; Anti-PD-1 Monoclonal Antibody) in Patients with Advanced Solid Tumors. Clin Cancer Res 2015;21:4286-93.

55. Hamid O, Robert C, Daud A, et al. Safety and tumor responses with lambrolizumab (anti-PD-1) in melanoma. N Engl J Med 2013;369:134-44.

56. Ribas A, Puzanov I, Dummer R, et al. Pembrolizumab versus investigator-choice chemotherapy for ipilimumabrefractory melanoma (KEYNOTE-002): a randomised, controlled, phase 2 trial. Lancet Oncol 2015;16:908-18.

57. Robert C, Ribas A, Schachter J, et al. Pembrolizumab versus ipilimumab in advanced melanoma

(KEYNOTE-006): post-hoc 5-year results from an openlabel, multicentre, randomised, controlled, phase 3 study. Lancet Oncol 2019;20:1239-51.

58. Gandhi L, Rodríguez-Abreu D, Gadgeel S, et al. KEYNOTE-189 Investigators. Pembrolizumab plus Chemotherapy in Metastatic Non-Small-Cell Lung Cancer. N Engl J Med 2018;378:2078-92.

59. Baxi S, Yang A, Gennarelli RL, et al. Immune-related adverse events for anti-PD-1 and anti-PD-L1 drugs: systematic review and meta-analysis. BMJ 2018;360:k793.

60. Weber JS, Kahler KC, Hauschild A. Management of immune-related adverse events and kinetics of response with ipilimumab. J Clin Oncol 2012;30:2691-7.

61. Shaverdian N, Lisberg AE, Bornazyan K, et al. Previous radiotherapy and the clinical activity and toxicity of pembrolizumab in the treatment of non-small-cell lung cancer: a secondary analysis of the KEYNOTE-001 phase 1 trial. Lancet Oncol 2017;18:895-903.

62. Kähler KC, Hassel JC, Heinzerling L, et al. "Cutaneous Side Effects" Committee of the Work Group Dermatological Oncology (ADO). Management of side effects of immune checkpoint blockade by anti-CTLA-4 and anti-PD-1 antibodies in metastatic melanoma. J Dtsch Dermatol Ges 2016;14:662-81.

63. Robert C, Ribas A, Wolchok JD, et al. Anti-programmeddeath-receptor-1 treatment with pembrolizumab in 
ipilimumab-refractory advanced melanoma: a randomised dose-comparison cohort of a Phase 1 trial. Lancet 2014;384:1109-17.

64. Michot JM, Bigenwald C, Champiat S, et al. Immunerelated adverse events with immune checkpoint blockade: a comprehensive review. Eur J Cancer 2016;54:139-48.

65. Chen J, Jiang CC, Jin L, et al. Regulation of PD-L1: a novel role of pro-survival signalling in cancer. Ann Oncol 2016;27:409-16.

66. Deng R, Bumbaca D, Pastuskovas CV, et al. Preclinical pharmacokinetics, pharmacodynamics, tissue distribution, and tumor penetration of anti-PD-L1 monoclonal antibody, an immune checkpoint inhibitor. MAbs 2016;8:593-603.

67. Herbst RS, Soria JC, Kowanetz M, et al. Predictive correlates of response to the anti-PD-L1 antibody MPDL3280A in cancer patients. Nature 2014;515:563-7.

68. Powles T, Eder JP, Fine GD, et al. MPDL3280A (antiPD-L1) treatment leads to clinical activity in metastatic bladder cancer. Nature 2014;515:558-62.

69. Rosenberg JE, Hoffman-Censits J, Powles T, et al. Atezolizumab in patients with locally advanced and metastatic urothelial carcinoma who have progressed following treatment with platinum-based chemotherapy: a single-arm, multicentre, phase 2 trial. Lancet 2016;387:1909-20.

70. Fehrenbacher L, Spira A, Ballinger M, et al. POPLAR Study Group. Atezolizumab versus docetaxel for patients with previously treated non-small-cell lung cancer (POPLAR): a multicentre, open-label, phase 2 randomised controlled trial. Lancet 2016;387:1837-46.

71. Rittmeyer A, Barlesi F, Waterkamp D, et al. OAK Study Group. Atezolizumab versus docetaxel in patients with previously treated non-small-cell lung cancer (OAK): a phase 3, open-label, multicentre randomised controlled trial. Lancet 2017;389:255-65.

72. Socinski MA, Jotte RM, Cappuzzo F, et al. IMpower 150 Study Group. Atezolizumab for First-Line Treatment of Metastatic Nonsquamous NSCLC. N Engl J Med 2018;378:2288-2301.

73. Horn L, Mansfield AS, Szcz sna A, et al. IMpower133 Study Group. First-Line Atezolizumab plus Chemotherapy in Extensive-Stage Small-Cell Lung Cancer. N Engl J Med 2018;379:2220-9.

74. Stewart R, Morrow M, Hammond SA, et al. Identification and Characterization of MEDI4736, an Antagonistic Anti-PD-L1 Monoclonal Antibody. Cancer Immunol Res 2015;3:1052-62.
75. Massard C, Gordon MS, Sharma S, et al. Safety and Efficacy of Durvalumab (MEDI4736), an AntiProgrammed Cell Death Ligand-1 Immune Checkpoint Inhibitor, in Patients With Advanced Urothelial Bladder Cancer. J Clin Oncol 2016;34:3119-25.

76. Powles T, O'Donnell PH, Massard C, et al. Efficacy and Safety of Durvalumab in Locally Advanced or Metastatic Urothelial Carcinoma: Updated Results From a Phase 1/2 Open-label Study. JAMA Oncol 2017;3:e172411.

77. Antonia SJ, Villegas A, Daniel D, et al. PACIFIC Investigators. Overall Survival with Durvalumab after Chemoradiotherapy in Stage III NSCLC. N Engl J Med 2018;379:2342-50.

78. Boyerinas B, Jochems C, Fantini M, et al. AntibodyDependent Cellular Cytotoxicity Activity of a Novel AntiPD-L1 Antibody Avelumab (MSB0010718C) on Human Tumor Cells. Cancer Immunol Res 2015;3:1148-57.

79. Heery CR, O'Sullivan-Coyne G, Madan RA, et al. Avelumab for metastatic or locally advanced previously treated solid tumours (JAVELIN Solid Tumor): a phase 1a, multicohort, dose-escalation trial. Lancet Oncol 2017;18:587-98.

80. Disis ML, Taylor MH, Kelly K, et al. Efficacy and Safety of Avelumab for Patients With Recurrent or Refractory Ovarian Cancer: Phase 1b Results From the JAVELIN Solid Tumor Trial. JAMA Oncol 2019;5:393-401.

81. Bang Y-J, Yañez Ruiz E, Van Cutsem E, et al. Phase III, randomised trial of avelumab versus physician's choice of chemotherapy as third-line treatment of patients with advanced gastric or gastro-oesophageal junction cancer: primary analysis of JAVELIN Gastric 300. Ann Oncol 2018;29:2052-60.

82. Barlesi F, Vansteenkiste J, Spigel D, et al. Avelumab versus docetaxel in patients with platinum-treated advanced non-small-cell lung cancer (JAVELIN Lung 200): an open-label, randomised, phase 3 study. Lancet Oncol 2018;19:1468-79.

83. Parry RV, Chemnitz JM, Frauwirth KA, et al. CTLA-4 and $\mathrm{PD}-1$ receptors inhibit $\mathrm{T}$-cell activation by distinct mechanisms. Mol Cell Biol 2005;25:9543-53.

84. Riley JL.Combination checkpoint blockade--taking melanoma immunotherapy to the next level. N Engl J Med 2013;369:187-9.

85. Wolchok JD, Kluger H, Callahan MK, et al. Nivolumab plus ipilimumab in advanced melanoma. N Engl J Med 2013;369:122-33.

86. Hodi FS, Chiarion-Sileni V, Gonzalez R, et al. Nivolumab plus ipilimumab or nivolumab alone versus ipilimumab 
alone in advanced melanoma (CheckMate 067): 4-year outcomes of a multicentre, randomised, phase 3 trial. Lancet Oncol 2018;19:1480-92.

87. Lebbé C, Meyer N, Mortier L, et al. Evaluation of Two Dosing Regimens for Nivolumab in Combination With Ipilimumab in Patients With Advanced Melanoma: Results From the Phase IIIb/IV CheckMate 511 Trial. J Clin Oncol 2019;37:867-75.

88. Carlino MS, Menzies AM, Atkinson V, et al. Longterm Follow-up of Standard-Dose Pembrolizumab Plus Reduced-Dose Ipilimumab in Patients with Advanced Melanoma: KEYNOTE-029 Part 1B. Clin Cancer Res 2020;26:5086-91.

89. Ribas A, Hodi FS, Callahan M, et al. Hepatotoxicity with combination of vemurafenib and ipilimumab. N Engl J Med 2013;368:1365-6.

90. Amin A, Lawson DH, Salama AKS, et al. Phase II study of vemurafenib followed by ipilimumab in patients with previously untreated BRAF-mutated metastatic melanoma. J Immunother Cancer 2016;4:44.

91. Ribas A, Butler M, Lutzky J, et al. Phase I study combining anti-PD-L1 (MEDI4736) with BRAF (dabrafenib) and/ or MEK (trametinib) inhibitors in advanced melanoma. J Clin Oncol 2015;33:3003.

92. Long GV, Hamid O, Hodi FS, et al. Phase 2 study of the safety and efficacy of pembrolizumab (pembro) in combination with dabrafenib (D) and trametinib (T) for advanced melanoma (KEYNOTE-022). J Clin Oncol 2016;34:Abstract TPS9596.

93. Hwu P, Hamid O, Gonzalez R, et al. Preliminary safety and clinical activity of atezolizumab combined with cobimetinib and vemurafenib in BRAF V600-mutant metastatic melanoma. Ann Oncol 2016;27:vi379-vi400.

94. Gutzmer R, Stroyakovskiy D, Gogas H, et al. Atezolizumab, vemurafenib, and cobimetinib as firstline treatment for unresectable advanced BRAF(V600) mutation-positive melanoma (IMspire150): primary analysis of the randomised, double-blind, placebocontrolled, phase 3 trial. Lancet 2020;395:1835-44.

95. Kiess AP, Wolchok JD, Barker CA, et al. Stereotactic radiosurgery for melanoma brain metastases in patients receiving ipilimumab: safety profile and efficacy of combined treatment. Int J Radiat Oncol Biol Phys 2015;92:368-75.

96. Ibrahim RA, Berman DM, DePril V, et al. Ipilimumab safety profile: summary of findings from completed trials in advanced melanoma. J Clin Oncol 2011;29:8583.

97. Villadolid J, Amin A. Immune checkpoint inhibitors in clinical practice: update on management of immunerelated toxicities. Transl Lung Cancer Res 2015;4:560-75.

98. Robert C, Long GV, Brady B, et al. Nivolumab in previously untreated melanoma without BRAF mutation. N Engl J Med 2015;372:320-30.

99. Robert C, Schachter J, Long GV, et al. KEYNOTE-006 investigators. Pembrolizumab versus Ipilimumab in Advanced Melanoma. N Engl J Med 2015;372:2521-32.

100. Weber JS, D'Angelo SP, Minor D, et al. Nivolumab versus chemotherapy in patients with advanced melanoma who progressed after anti-CTLA-4 treatment (CheckMate 037): a randomised, controlled, open-label, phase 3 trial. Lancet Oncol 2015;16:375-84.

101. Weber J. Ipilimumab: controversies in its development, utility and autoimmune adverse events. Cancer Immunol Immunother 2009;58:823-30.

102.Vieth M, Montgomery E. Medication-associated gastrointestinal tract injury. Virchows Arch 2017;470:245-66.

103. Berman D, Parker SM, Siegel J, et al. Blockade of cytotoxic T-lymphocyte antigen-4 by ipilimumab results in dysregulation of gastrointestinal immunity in patients with advanced melanoma. Cancer Immun 2010;10:11.

104. García-Varona A, Odze RD, Makrauer F. Lymphocytic colitis secondary to ipilimumab treatment. Inflamm Bowel Dis 2013;19:E15-6.

105. Gonzalez RS, Salaria SN, Bohannon CD, et al. PD-1 inhibitor gastroenterocolitis: case series and appraisal of 'immunomodulatory gastroenterocolitis'. Histopathology 2017;70:558-67.

106. Marthey L, Mateus C, Mussini C, et al. Cancer Immunotherapy with Anti-CTLA-4 Monoclonal Antibodies Induces an Inflammatory Bowel Disease. J Crohns Colitis 2016;10:395-401.

107. Collins M, Michot JM, Danlos FX, et al. Inflammatory gastrointestinal diseases associated with PD-1 blockade antibodies. Ann Oncol 2017;28:2860-5.

108. Kim KW, Ramaiya NH, Krajewski KM, et al. Ipilimumabassociated colitis: CT findings. AJR Am J Roentgenol 2013;200:W468-74.

109.Postow MA. Managing immune checkpoint-blocking antibody side effects. Am Soc Clin Oncol Educ Book 2015;76-83.

110. Wolchok JD, Neyns B, Linette G, et al. Ipilimumab monotherapy in patients with pretreated advanced melanoma: a randomised, double-blind, multicentre, phase 2, dose-ranging study. Lancet Oncol 2010;11:155-64.

111. Ascierto PA, Del Vecchio M, Mackiewicz A, et al. 
Overall survival at 5 years of follow-up in a phase III trial comparing ipilimumab $10 \mathrm{mg} / \mathrm{kg}$ with $3 \mathrm{mg} / \mathrm{kg}$ in patients with advanced melanoma. J Immunother Cancer 2020;8:e000391.

112.Eggermont AMM, Chiarion-Sileni V, Grob JJ, et al. Adjuvant ipilimumab versus placebo after complete resection of high-risk stage III melanoma (EORTC 18071): a randomised, double-blind, phase 3 trial. Lancet Oncol 2015;16:522-30.

113. Johncilla M, Misdraji J, Pratt DS, et al. Ipilimumabassociated Hepatitis: Clinicopathologic Characterization in a Series of 11 Cases. Am J Surg Pathol 2015;39:1075-84.

114. De Martin E, Michot JM, Papouin B, et al. Characterization of liver injury induced by cancer immunotherapy using immune checkpoint inhibitors. J Hepatol 2018;68:1181-90.

115.Gauci ML, Baroudjian B, Zeboulon C, et al. PATIO group. Immune-related hepatitis with immunotherapy: Are corticosteroids always needed? J Hepatol 2018;69:548-550.

116. Boutros C, Tarhini A, Routier E, et al. Safety profiles of anti-CTLA-4 and anti-PD-1 antibodies alone and in combination. Nat Rev Clin Oncol 2016;13:473-86.

117.Hofmann L, Forschner A, Loquai C, et al. Cutaneous, gastrointestinal, hepatic, endocrine, and renal side-effects of anti-PD-1 therapy. Eur J Cancer 2016;60:190-209.

118.Imafuku K, Yoshino K, Yamaguchi K, et al. Successful Treatment of Sudden Hepatitis Induced by LongTerm Nivolumab Administration. Case Rep Oncol 2017;10:368-71.

119. Wu Z, Lai L, Li M, et al. Acute liver failure caused by pembrolizumab in a patient with pulmonary metastatic liver cancer: A case report. Medicine (Baltimore) 2017;96:e9431.

120.Postow MA, Sidlow R, Hellmann MD. Immune-Related Adverse Events Associated with Immune Checkpoint Blockade. N Engl J Med 2018;378:158-68.

121. Topalian SL, Taube JM, Anders RA, et al. Mechanismdriven biomarkers to guide immune checkpoint blockade in cancer therapy. Nat Rev Cancer 2016;16:275-87.

122.Everett J, Srivastava A, Misdraji J. Fibrin Ring Granulomas in Checkpoint Inhibitor-induced Hepatitis. Am J Surg Pathol 2017;41:134-7.

123. Gelsomino F, Vitale G, D'Errico A, et al. Nivolumabinduced cholangitic liver disease: a novel form of serious liver injury. Ann Oncol 2017;28:671-2.

124. Kawakami H, Tanizaki J, Tanaka K, et al. Imaging and clinicopathological features of nivolumab-related cholangitis in patients with non-small cell lung cancer. Invest New Drugs 2017;35:529-36.

125. Kleiner DE, Berman D. Pathologic changes in ipilimumab-related hepatitis in patients with metastatic melanoma. Dig Dis Sci 2012;57:2233-40.

126. Friedman CF, Proverbs-Singh TA, Postow MA. Treatment of the Immune-Related Adverse Effects of Immune Checkpoint Inhibitors: A Review. JAMA Oncol 2016;2:1346-53.

127. Suzuki A, Brunt EM, Kleiner DE, et al. The use of liver biopsy evaluation in discrimination of idiopathic autoimmune hepatitis versus drug-induced liver injury. Hepatology 2011;54:931-9.

128. Cramer P, Bresalier RS. Gastrointestinal and Hepatic Complications of Immune Checkpoint Inhibitors. Curr Gastroenterol Rep 2017;19:3.

129. Friedman CF, Clark V, Raikhel AV, et al. Thinking Critically About Classifying Adverse Events: Incidence of Pancreatitis in Patients Treated With Nivolumab + Ipilimumab. J Natl Cancer Inst 2016;109:djw260.

130. Champiat S, Lambotte O, Barreau E, et al. Management of immune checkpoint blockade dysimmune toxicities: a collaborative position paper. Ann Oncol 2016;27:559-74.

131. Cooley L, Dendle C, Wolf J, et al. Consensus guidelines for diagnosis, prophylaxis and management of Pneumocystis jirovecii pneumonia in patients with haematological and solid malignancies, 2014. Intern Med J 2014;44:1350-63. Corrected in Intern Med J 2014;45:469.

132. Weber JS, Postow M, Lao CD, et al. Management of Adverse Events Following Treatment With AntiProgrammed Death-1 Agents. Oncologist 2016;21:1230-40.

133.Pagès C, Gornet JM, Monsel G, et al. Ipilimumab-induced acute severe colitis treated by infliximab. Melanoma Res 2013;23:227-30.

134. Targownik LE, Bernstein CN. Infectious and malignant complications of TNF inhibitor therapy in IBD. Am J Gastroenterol 2013;108:1835-42.

135. Good-Jacobson KL, Szumilas CG, Chen L, et al. PD-1 regulates germinal center $\mathrm{B}$ cell survival and the formation and affinity of long-lived plasma cells. Nat Immunol 2010;11:535-42.

136. Baroudjian B, Lourenco N, Pagès C, et al. Anti-PD1induced collagenous colitis in a melanoma patient. Melanoma Res 2016;26:308-11.

137.Postow MA, Chesney J, Pavlick AC, et al. Nivolumab and ipilimumab versus ipilimumab in untreated melanoma. $\mathrm{N}$ Engl J Med 2015;372:2006-17.

138. Turner D, Walsh CM, Steinhart AH, et al. Response to 
corticosteroids in severe ulcerative colitis: a systematic review of the literature and a meta-regression. Clin Gastroenterol Hepatol 2007;5:103-10.

139. Weber J, Thompson JA, Hamid O, et al. A randomized, double-blind, placebo-controlled, phase II study comparing the tolerability and efficacy of ipilimumab administered with or without prophylactic budesonide in patients with unresectable stage III or IV melanoma. Clin Cancer Res 2009;15:5591-8.

140.Pollack MH, Betof A, Dearden H, et al. Safety of resuming anti-PD-1 in patients with immune-related adverse events (irAEs) during combined anti-CTLA-4 and anti-PD1 in metastatic melanoma. Ann Oncol 2018;29:250-5.

141. Horvat TZ, Adel NG, Dang T-O, et al. Immune-Related Adverse Events, Need for Systemic Immunosuppression, and Effects on Survival and Time to Treatment Failure in Patients With Melanoma Treated With Ipilimumab at Memorial Sloan Kettering Cancer Center. J Clin Oncol 2015;33:3193-8.

142. Gupta A, De Felice KM, Loftus Jr EV, et al. Systematic review: colitis associated with anti-CTLA-4 therapy.

Cite this article as: Boussios S, Sheriff M, Rassy E, Moschetta M, Samartzis EP, Hallit R, Sadauskaite A, Katsanos KH, Christodoulou DK, Pavlidis N. Immuno-oncology: a narrative review of gastrointestinal and hepatic toxicities. Ann Transl Med 2021;9(5):423. doi: 10.21037/atm-20-7361
Aliment Pharmacol Ther 2015;42:406-17.

143. Haanen JBAG, Carbonnel F, Robert C, et al. ESMO Guidelines Committee. Management of toxicities from immunotherapy: ESMO Clinical Practice Guidelines for diagnosis, treatment and follow-up. Ann Oncol 2017;28:iv119-iv142.

144. Puzanov I, Diab A, Abdallah K, et al. Society for Immunotherapy of Cancer Toxicity Management Working Group. Managing toxicities associated with immune checkpoint inhibitors: consensus recommendations from the Society for Immunotherapy of Cancer (SITC) Toxicity Management Working Group. J Immunother Cancer 2017;5:95.

145. Chmiel KD, Suan D, Liddle C, et al. Resolution of severe ipilimumab-induced hepatitis after antithymocyte globulin therapy. J Clin Oncol 2011;29:e237-40.

146.Ziemer M, Koukoulioti E, Beyer S, et al. Managing immune checkpoint-inhibitor-induced severe autoimmune-like hepatitis by liver-directed topical steroids. J Hepatol 2017;66:657-9. 